\title{
Recent development of collective Thomson scattering for magnetically confined fusion plasmas
}

Nielsen, Stefan Kragh; Michelsen, Poul; Hansen, S.K.; Korsholm, Søren Bang; Leipold, Frank; Rasmussen, Jesper; Salewski, Mirko; Schubert, Martin; Pedersen, Morten Stejner; Stober, J. Total number of authors:

11

Published in:

Physica Scripta

Link to article, DOI:

$10.1088 / 1402-4896 / 92 / 2 / 024001$

Publication date:

2017

Document Version

Early version, also known as pre-print

Link back to DTU Orbit

Citation (APA):

Nielsen, S. K., Michelsen, P., Hansen, S. K., Korsholm, S. B., Leipold, F., Rasmussen, J., Salewski, M., Schubert, M., Pedersen, M. S., Stober, J., \& Wágner, D. S. (2017). Recent development of collective Thomson scattering for magnetically confined fusion plasmas. Physica Scripta, 92(2), [024001].

https://doi.org/10.1088/1402-4896/92/2/024001

\section{General rights}

Copyright and moral rights for the publications made accessible in the public portal are retained by the authors and/or other copyright owners and it is a condition of accessing publications that users recognise and abide by the legal requirements associated with these rights.

- Users may download and print one copy of any publication from the public portal for the purpose of private study or research.

- You may not further distribute the material or use it for any profit-making activity or commercial gain

- You may freely distribute the URL identifying the publication in the public portal 
This document is intended for publication in the open literature. It is made available on the clear understanding that it may not be further circulated and extracts or references may not be published prior to publication of the original when applicable, or without the consent of the Publications Officer, EUROfusion Programme Management Unit, Culham Science Centre, Abingdon, Oxon, OX14 3DB, UK or e-mail Publications.Officer@euro-fusion.org

Enquiries about Copyright and reproduction should be addressed to the Publications Officer, EUROfusion Programme Management Unit, Culham Science Centre, Abingdon, Oxon, OX14 3DB, UK or e-mail Publications.Officer@euro-fusion.org

The contents of this preprint and all other EUROfusion Preprints, Reports and Conference Papers are available to view online free at http://www.euro-fusionscipub.org. This site has full search facilities and e-mail alert options. In the JET specific papers the diagrams contained within the PDFs on this site are hyperlinked 


\title{
Recent development of Collective Thomson scattering for magnetically confined fusion plasmas
}

\author{
S K Nielsen ${ }^{1}$, P K Michelsen ${ }^{1}$, S K Hanssen ${ }^{1,2}$, S B \\ Korsholm $^{1}$, F Leipold ${ }^{1}, \mathrm{~J}_{\text {Rasmussen }}{ }^{1}, \mathrm{M}$ Salewski $^{1}, \mathrm{M}$ \\ Schubert $^{2}$, M Stejner ${ }^{1}, \mathrm{~J}_{\text {Stober }}{ }^{2}, \mathrm{D}$ Wagner $^{2}$, and the \\ ASDEX Upgrade team ${ }^{2}$ \\ 1 Technical University of Denmark, Department of Physics, DK-2800 Lyngby, \\ Denmark \\ 2 Max-Planck-Institut für Plasmaphysik, D-85748 Garching, Germany \\ E-mail: skni@fysik.dtu.dk \\ September 2016
}

\begin{abstract}
Here we review recent experimental development within the field of collective Thomson scattering with focus on the progress made on the devices TEXTOR and ASDEX Upgrade. We discuss recently discovered possibilities and limitations of the diagnostic technique. Diagnostic applications with respect to ion measurements are demonstrated. Examples include measurements of the ion temperature, energetic ion distribution function, and the ion composition.
\end{abstract}

Submitted to: Phys. Scr. 


\section{Introduction}

Reliable measurements from the centre of a laboratory plasma with a temperature of millions of degrees Kelvin are in general difficult to obtain. Accessibility issues and the harsh environment near the plasma often make it impossible to apply conventional techniques. Scattering of photon beams is widely used in high temperature plasmas to obtain information about the particle distribution functions in the core of the plasma [1]. Furtherm,ore diagnostics based on microwave techniques are known to be well suited in plasma environments envisioned in future fusion power plants based on magnetic confinement [2].

The collective Thomson scattering (CTS) technique has advanced significantly over the last 10 years. Here high power microwave beams scatter off fluctuations in the plasma which are mainly driven by the ion dynamics. The ion velocity causes the scattering radiation to be Doppler shifted and a number of plasma properties can be inferred from the detected CTS spectra.

The main emphasis in the development of the CTS diagnostic for tokamak relevant conditions is the need to diagnose the energetic alpha particles which are produced in the deuterium-tritium fusion process [3], the main reaction both for the ITER tokamak and first generation fusion power plants. Despite their low number density, the alpha particles have important consequences for plasma confinement and stability due to the their large energies. Generally, confined energetic ions may drive plasma currents and affect the stability threshold of a number of plasma instabilities $[4,5]$ while poorly confined energetic ions may damage the machine. On the other hand, alpha particles will be the dominant source of plasma heating in a fusion reactor, and it is therefore necessary to ensure that they stay confined for long enough to deposit their energy in the plasma. As fusion reactions occur at negligible rates in most experimental facilities, energetic particles from neutral beam injection are studied by CTS instead [6-9]. CTS measurements are now also used in joint tomographic inversions together with fast-ion D-alpha measurements to measure 2D velocity distribution functions [10-12].

An additional application of the CTS diagnostic is the characterization of the bulk-ion parameters such as main ion temperature, main ion drift velocity, and bulk ion composition [13]. These measurements are particularly relevant for stellarator devices due to the general difficulty in diagnosing ion temperatures at high electron densities. In tokamas such measurements have been demonstrated on the TEXTOR and the ASDEX Upgrade devices [14,15]. Presently, bulk ion CTS measurements are also being made at the stellarator LHD [16] and the tokamak FTU [17]. Additionally, CTS systems are being developed for the high-profile machines Wendelstein 7X and ITER.

In this paper we will review the experimental development of the CTS technique with the focus on the TEXTOR and the ASDEX Upgrade devices. We will show examples of successful characterization of the fast ions, the temperature, the drift velocity and the fuel composition. Finally, we will address experimental pitfalls in the field of CTS.

\section{Principle of collective Thomson scattering}

Charged particles set up fluctuations in the plasma density, magnetic field, electric field and the particle flux which may be resolved by scattering. Collective fluctuations with length scales larger than the Debye length, $1 / k^{\delta}>\lambda_{D}$, are mainly driven by 


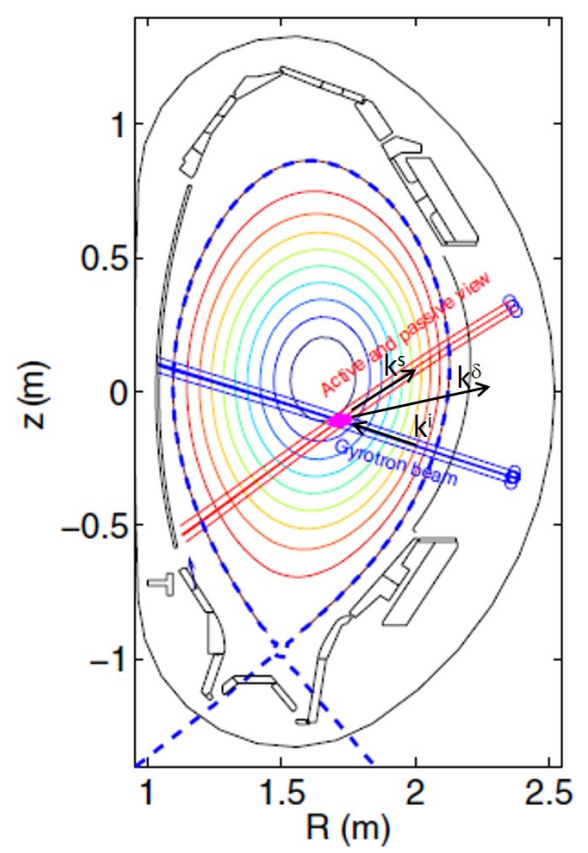

Figure 1. Example of scattering geometry for CTS at ASDEX Upgrade.The difference between the k-vectors defines $k^{\delta}$, the resolved direction. Figure modified from $[8]$.

the ion motion. Here $k^{\delta}$ is the length of the fluctuation wave vector and $\lambda_{D}$ is the Debye length. The resolved fluctuation in a scattering experiment is determined by the scattering geometry (the Bragg condition): $\mathbf{k}^{\delta}=\mathbf{k}^{\mathbf{s}}-\mathbf{k}^{\mathbf{i}}$, where $\mathbf{k}^{\mathbf{i}}$ and $\mathbf{k}^{\mathbf{s}}$ are the wave vectors of the incident and scattered waves, respectively. The choice of the incident and scattering wave vector, together with the angle between $\mathbf{k}^{\mathbf{s}}$ and $\mathbf{k}^{\mathbf{i}}$, determine if the scattering is collective. In CTS the frequency of the detected radiation, $\nu^{s}=\nu^{i}+\nu^{\delta}$, is approximately determined by $\nu^{\delta} \approx \mathbf{v}_{\mathbf{i}} \cdot \mathbf{k}^{\delta} / 2 \pi$ due to the Doppler shift of the ion with velocity $\mathbf{v}_{\mathbf{i}}$. An example of a scattering geometry from ASDEX Upgrade is shown in figure 1.

The scattering spectra contain different types of information which in many cases can be extracted for the experiment. For specific scattering geometries the spectra contain information about the one dimensional projection of the $3 \mathrm{D}$ ion velocity distribution function onto the resolved fluctuation vector, $\mathbf{k}^{\delta}$. The rotational symmetry of the $3 \mathrm{D}$ ion velocity distribution function suggests that the diagnostic can be optimized to measure particular energy and pitch ranges of the fast ions. This is quantified by so-called weight functions [18]. The projected fast-ion velocity distribution function can thus be obtained from the tail of the scattering spectrum. From the width of the bulk part of the scattering spectrum, the ion temperature can be evaluated and the drift of the plasma can be estimated from the shift of the bulk spectrum. For specific geometries, where the resolved fluctuation is approximately perpendicular to the magnetic field, the ion composition can also be extracted from the spectrum [13]. 


\section{Technical challenges associated with CTS measurements}

\subsection{Resonances}

The high power incident radiation required for CTS is typically generated by gyrotrons in the mm-wave region with powers up to a megawatt. In magnetic confinement plasmas the electrons emit cyclotron radiation in the mm-wave region. This means that potential absorption of the probe beam must be considered when designing scattering experiments, and that background due to mm-wave electron cyclotron emission (ECE) must be accounted for in the data analysis. Other resonances, such as the upper hybrid resonance, may also affect the ability to measure CTS spectra as will be discussed later.

In the working scenarios for fast-ion CTS at TEXTOR and ASDEX Upgrade, where a low ECE background radiation is required in order to obtain acceptable signal-to-noise ratio, the gyrotron beam has effectively been operating between the fundamental and second harmonic ECE resonance. For bulk-ion CTS an acceptable signal-to-noise ratio may be achieved with an optically thick ECE resonance within the plasma, as long as the scattering volume (overlap between probe radiation and receiver view) is located between the probe launcher mirror and the resonance.

\subsection{Gyrotron and radiometer requirement}

During the firs micro seconds after switching on a gyrotron the frequency typically drifts several hundreds $\mathrm{MHz}$ while the power increases. Once a stable gyrotron power level is reached the gyrotron frequency generally drifts additional tens of $\mathrm{MHz}$ [19]. The gyrotron power level is generally about 16 orders of magnitude above the power level of the detected CTS signal. Notch filters are used to attenuate the gyrotron frequency to protect the receiver electronics and to allow detection of the relatively small CTS signal. The frequency width of the notch filters is a critical parameter in order to obtain a good CTS spectrum. If the width is too large, no bulk CTS signal is observed and the data treatment is difficult. If the width is too small, the gyrotron is not attenuated by the notch filter and the receiver electronics will be damaged or driven into saturation. On the TEXTOR and ASDEX Upgrade experiment, where the bulk CTS spectrum has a typical width of 0.5 to $1 \mathrm{GHz}$, notch filter widths of 200-300 MHz were used and an additional fast-switching broadband attenuator (like a PIN diode) attenuates the first 100 microseconds of the gyrotron probe time. We may note that, at TEXTOR and ASDEX Upgrade, the most successful CTS operation is obtained with short $2 \mathrm{~ms}$ pulses from the gyrotron. Longer gyrotron pulses have in some cases resulted in high power signals in the detection system which are difficult to interpret.

\subsection{Sensitive Radiometers}

The fast-ion component in CTS spectra is typically small compared to the bulk-ion signal (due to the relatively low fast-ion number density), and it dominates only at relatively large frequency shifts. The CTS scattering power, in the direction of the receiver, is typically in the order of nanowatts which should be compared to a megawatt of probing power. Additionally, the plasma background radiation may easily be two orders of magnitude higher than the scattering signal of interest. A strong focus on maintaining detection linearity, avoiding gain compression, filtering of unwanted 
signals, and high sensitivity of the detection system are thus prerequisites for successful CTS measurements.

In this paper we primarily show examples from the CTS system installed at the ASDEX Upgrade tokamak. Here a gyrotron of the heating system delivers the CTS probing radiation [20]. The gyrotron is operated at $105 \mathrm{GHz}$ with a typical power of $600 \mathrm{~kW}$ and is generally found to fulfil all the strict requirements with respect to purity, beam shape, and frequency stability. Both probe and receiver are typically operated in O-mode. However, successful detection of X to X-mode scattering during second harmonic heating has recently been demonstrated at ASDEX Upgrade [?]. In the following we will focus on $\mathrm{O}$ to O-mode scattering. The CTS receivers at ASDEX Upgrade are heterodyne radiometers and are discussed in reference [21,22].

\section{Sources of additional signals}

The initial operation of the CTS diagnostic at ASDEX upgrade resulted in observation of signals not described by the CTS theory $[23,24]$. This residual signal was independent of the magnitude and the position of the overlap between the probe radiation and the receiver view.

In general, two types of residual signals were observed. The first type is associated with the secondary harmonic ECE resonance being slightly in the plasma on the high field side. Here, a small (few eV) broadband signal is observed, likely to be associated with subsequently heating by the probing gyrotron and enhanced ECE emission by the plasma. This residual signal is now measured using a passive view to monitor the ECE emission during gyrotron operation and can hence be subtracted from the CTS measurements [8].

A much stronger residual signal, with spectral power densities up to the $\mathrm{MeV}$ range, is observed when the reflected gyrotron radiation approaches the upper hybrid resonance on the high field side. Here, parametric decay of the gyrotron radiation converted from O-mode to X-mode at the wall reflection takes place. Recent numerical investigations [25] indicate that power levels down to $\mathrm{kW}$ of gyrotron radiation may

decay into an electron Bernstein wave and a lower hybrid wave. Mode conversion of the electron Bernstein wave together with scattering of the probe radiation off the excited lower hybrid wave give rise to the strong residual signals.

The theory of the parametric decay during CTS measurements is supported by the nature of the detected radiation. The strong residual signal is mitigated in scattering experiments where the wall reflected X-mode radiation is absorbed by the fundamental resonance before reaching the upper hybrid resonance. Also the frequency of the residual signal matches very well the frequency of the excited lower hybrid wave. An example of a relevant scattering geometry from ASDEX Upgrade is shown in figure 2 together with the measured spectrum. The dashed line at $0.85 \mathrm{GHz}$ below and above the gyrotron frequency at $105 \mathrm{GHz}$ marks the theoretical frequency for the observed signal from parametric decay into an electron Bernstein wave and a lower hybrid wave [25-27].

\section{Bulk ion CTS measurements}

In 1958, Bowles intended to measure the electron density and temperature using Thomson scattering of the ionosphere [28]. He intended to use backscattering of $41 \mathrm{MHz}$ radio waves to characterise the properties of the electron of the ionosphere. 

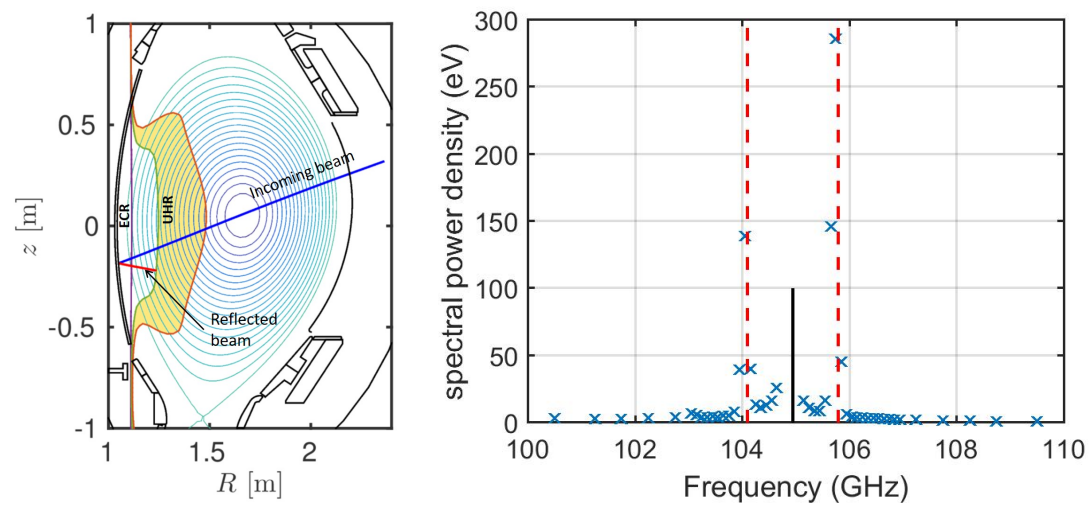

Figure 2. left: geometry of injected O-mode gyrotron beam (blue) and the trajectory of the wall reflected $\mathrm{X}$-mode fraction. The reflected beam propagates past the electron cyclotron resonance (ECR) and stops at the upper hybrid resonance where mode conversion and parametric decay can occur. Right: Corresponding measured spectrum (cross). The sum and difference between the gyrotron frequency and the predicted lower hybrid wave frequency $(0.85 \mathrm{GHz})$ are represented by the dotted lines, and the solid black line marks the gyrotron frequency.

However, the measurements showed that the width of the scattered radiation was a signature of the ionosphere ion features and not the electron features. This triggered theoretical development, and by 1960 Salpeter [29] showed that the observed spectrum could be explained by collective electron fluctuations shielding the ions. Throughout the 1960s, CTS experiments were carried out in various high density, low temperature plasma devices by forward scattering using Ruby lasers.

With the development of the tokamak, the need for localized ion temperature measurements grew. In the early 1970s, Jassby et al. [30] proposed that CTS could provide such measurements using far infrared lasers with $\lambda \sim 0.1-1 \mathrm{~mm}$. The low scattering cross section required a high power source and high frequency stability was also necessary. The first CTS ion temperature measurements were done in 1989 by Behn et al. [31] using a $\mathrm{D}_{2} \mathrm{O}$ far infrared laser $(\lambda \sim 0.4 \mathrm{~mm})$ in the TCA tokamak. This was, however, limited to one measurement per discharge. Woskov first proposed using gyrotrons for CTS [32]. The advantage of using gyrotrons is the longer pulse periods together with the longer wavelength which reduces the restrictions on the scattering geometry. In 1995, a $140 \mathrm{GHz}$ gyrotron $(\lambda \sim 2.1 \mathrm{~mm})$ was used to obtain the ion temperature in the stellarator W7-AS [33], and a year later ion temperature measurements were reported from JET [34] also using a $140 \mathrm{GHz}$ gyrotron.

The development of high speed digitizers with sampling rates above 5 GS/s and $\mathrm{GHz}$ wide analogue bandwidths open up for detection of the CTS microwave signals without the use of mechanical filters. By down-converting the signal of interest to a range between 0 and $2 \mathrm{GHz}$, the CTS signal can be digitized directly and the scattering spectra can be obtained from Fourier transform techniques. This was first done on the TEXTOR tokamak with a frequency resolution of sub $\mathrm{MHz}$ [35] and opened up for detailed ion temperature measurements, ion rotation measurements and plasma ion composition [36]. Similar systems have been installed on the ASDEX Upgrade tokamak and good agreement between charge-exchange based ion diagnostics and 


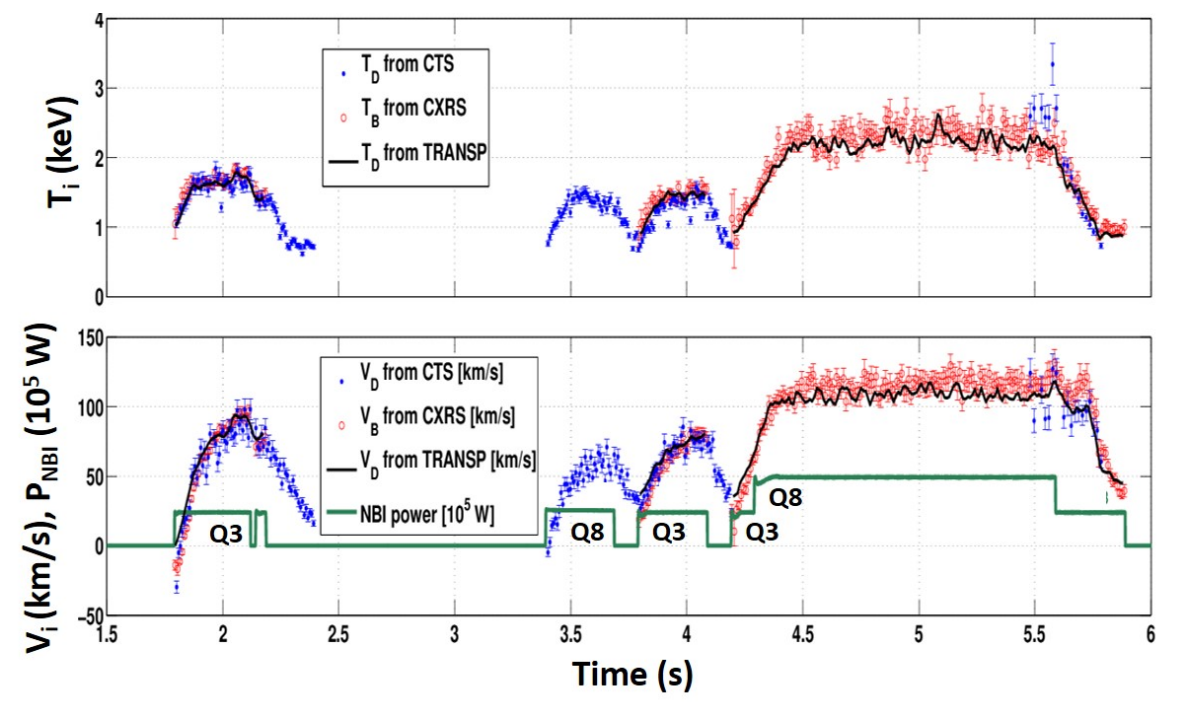

Figure 3. Example of inferred ion temperature and drift velocity from CTS and Charge exchange recombination spectroscopy. Q3 marks the NBI source 3 (60 $\mathrm{keV})$ and Q8 marks the NBI source $8(90 \mathrm{keV})$. Figure modified from [15].

CTS diagnostic are typically found [22]. An example of such agreement is shown in figure 3 .

\section{Bulk ion composition}

When the resolved wave vector is close to perpendicular to the background magnetic field, $\phi=\angle\left(\mathbf{k}^{\delta}, \mathbf{B}\right) \approx 90^{\circ}$, a number of waves can modify the CTS spectrum. Particularly, the ion Bernstein wave and the cyclotron motion of the ions leave a strong signature in the spectra. Since these signatures carry information about the relative densities of the main ion species, the plasma composition may be inferred from the measured spectra [13]. This was demonstrated on the TEXTOR tokamak [37] where different ion composition mixes were injected in the device and subsequently detected by the CTS diagnostic. In figure 4 we show examples of detected CTS spectra at $\phi=87^{\circ}$ (isotop-CTS) and a reference spectrum at $\phi=140^{\circ}$. We note that in the isotop-CTS geometry we see clear structures which are not present in the normal CTS geometry at $\phi=140^{\circ}$. Also, when the plasma is dominated by hydrogen ions, and no helium-3 is injected, the spectrum is modulated with the hydrogen cyclotron frequency of about $40 \mathrm{MHz}$. As the helium-3 level is increased the measured spectra become more complex. The helium-3 concentration in the plasma centre was in this case measured to $0 \%, 7 \%, 8 \%$, and $12 \%$ of the electron density, respectively.

This system has great potential with respect to measurement of the fusion fuel ions, deuterium and tritium, in future power plants. A systematic study of the possibility for such a diagnostic on ITER has been performed [14] and the technique is an obvious candidate for a diagnostic on ITER. 


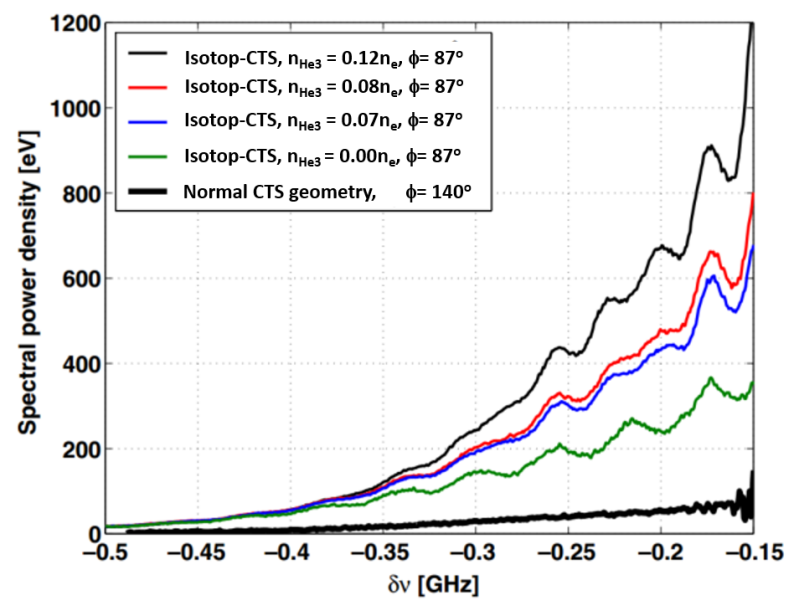

Figure 4. Measured CTS spectra for different main ion composition with a resolved wave vector close to perpendicular to B. For no He3 (green) the peaks separated by the hydrogen cyclotron frequency $(41 \mathrm{MHz})$ are clearly seen. As the He3 concentration is increased the complexity of the recorded spectra rises. Figure modified from [14].

\section{Fast ion measurement}

In 1984, it was proposed by Hutchinson et al. [38] that CTS additionally could be used as a fast ion diagnostic for diagnosing alpha particles. In the late 1980s, both TFTR and JET started installing gyrotron-based fast-ion CTS. TFTR suffered problems with the high power gyrotron and changed their approach to resolve fluctuations perpendicular to the magnetic field using a low power gyrotron [39]. Here the scattered radiation was expected to be enhanced by the lower hybrid wave. However, development in the scattering theory [40] found that this enhancement would be cancelled by the magnetic field fluctuations as later reported experimentally [41]. In 1999, the first fast ion CTS measurements of ICRH heated ions in JET were reported [42]. However, due to technical challenges at JET no fast alphas were measured. A high noise level in the data implied that the dynamics of the fast ions could not be resolved.

A breakthrough of fast-ion CTS was made on the TEXTOR tokamak where the dynamics of the fast ion distribution was measured [6]. Systematic studies of the beam ions show good agreement with classical slowing down [7] and the redistribution of beam ions during sawteeth crashes was successfully characterized $[43,44]$.

Following the success on TEXTOR, the ASDEX Upgrade tokamak was equipped with two CTS diagnostics targeting both bulk- and fast-ion measurements. Here the classical slowing down of neutral beam ions has so far been experimentally verified in MHD quiecent discharges $[8,9]$. Also good agreement are found between the ASDEX Upgrade fast-ion diagnostics CTS and FIDA [11]. In figure 5 the measured onedimensional distribution function during injection of 60 and $93 \mathrm{keV}$ beams is compared with TRANSP simulations.

The CTS systems on ASDEX Upgrade is being utilized within the European fusion program, EUROfusion, to characterize the detailed interplay between fast ions 


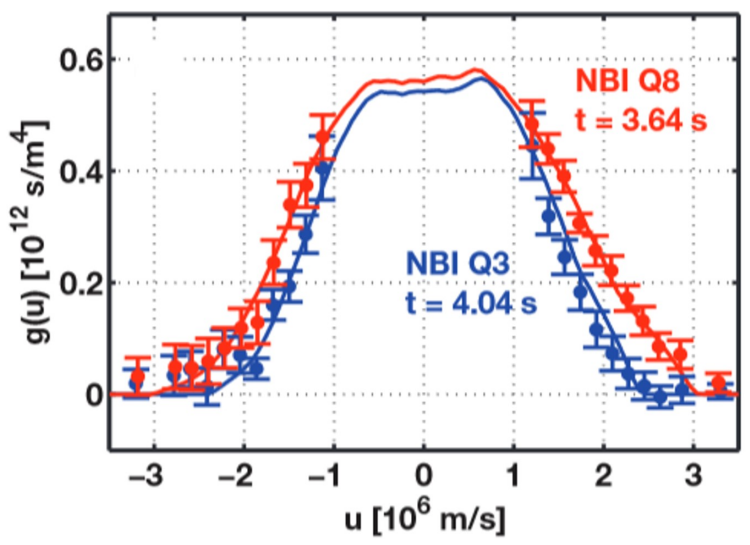

Figure 5. Example of inferred projected fast-ion velocity distribution for injection of $60 \mathrm{keV}$ ions (NBI Q3, blue) and $93 \mathrm{keV}$ ions (NBI Q8, red) at ASDEX Upgrade. Figure modified from [9].

and plasma instabilities. A special focus has been on the redistribution of fast ions by sawtooth crashes from both an experimental [12] and numerical [46] point of view. Alongside, the ASDEX Upgrade CTS system is a main player in maturing the CTS technique even further in the light of the diagnostic requirements for ITER and future fusion power plants.

\section{Conclusion}

During the recent years the CTS diagnostic has provided measurements of both the bulk- and the fast-ion velocity distribution. The experimental progress on the topic has shown that the receiver electronics must be highly suited for the task and that a number of interactions between the incoming high power radiation and the plasma may take place as seen on W7-AS [47], FTU [17], LHD [16], and ASDEX Upgrade [8]. All these considerations must be taken into account when designing CTS experiments. Nevertheless, the technique has recently been brought to a level where new CTS systems are being designed for devices like Wendelstein 7X and ITER.

Given the recent experimental progress in the field, and since CTS is a purely microwave based diagnostic, it is very likely that this technique will be a critical diagnostic for future fusion power plants.

\section{Acknowledgments}

This work has been carried out within the framework of the EUROfusion Consortium and has received funding from the Euratom research and training programme 20142018 under grant agreement No 633053. The views and opinions expressed herein do not necessarily reflect those of the European Commission.

\section{References}

[1] Hutchinson I 1987 Principles of plasma diagnostics (Cambridge University Press) 
[2] Hartfuss H J, Geist $\mathrm{T}$ and Hirsch M 1997 Plasma Physics and Controlled Fusion $39 \quad$ 1693-1769 ISSN 0741-3335 URL http://iopscience.iop.org.globalproxy.cvt.dk/0741-3335/39/11/001

[3] Salewski M, Eriksson L G, Bindslev H, Korsholm S, Leipold F, Meo F, Michelsen $\mathrm{P}$ and Nielsen S 2009 Nuclear Fusion 49025006 ISSN 0029-5515 URL http: //stacks.iop.org/0029-5515/49/i=2/a=025006

[4] Heidbrink W W and Sadler G 1994 Nuclear Fusion 34 535-615

[5] Pinches S D, Berk H L, Borba D N, Breizman B N, Briguglio S, Fasoli A, Fogaccia G, Gryaznevich M P, Kiptily V, Mantsinen M J, Sharapov S E, Testa D, Vann R G L, Vlad G and Zonca F 2004 Plasma Physics and Controlled Fusion 46 B187-B200

[6] Bindslev H, Nielsen S K, Porte L, Hoekzema J A, Korsholm S B, Meo F, Michelsen P K, Michelsen S, Oosterbeek J, Tsakadze E L, Westerhof E, Woskow P and the TEXTOR team 2006 Physical Review Letters 97 205005-1-2005005-4

[7] Nielsen S K, Bindslev H, Porte L, Hoekzema J A, Korsholm S B, Leipold F, Meo F, Michelsen P K, Michelsen S, Oosterbeek J W, Tsakadze E L, Van Wassenhove G, Westerhof E and Woskov P 2008 Physical Review E 77016407 ISSN 1539-3755 URL http://pre.aps.org.globalproxy.cvt.dk/abstract/PRE/v77/i1/e016407

[8] Nielsen S K, Stejner M, Rasmussen J, Jacobsen A S, Korsholm S B, Leipold F, Maraschek M, Meo F, Michelsen P K, Moseev D, Salewski M, Schubert M, Stober J, Suttrop W, Tardini G, Wagner D and Team A U 2015 Plasma Physics and Controlled Fusion 57 ISSN 0741$3335 ; 1361-6587$

[9] Rasmussen J, Nielsen S K, Stejner M, Geiger B, Salewski M, Jacobsen A S, Korsholm S B, Leipold F, Michelsen P K, Moseev D, Schubert M, Stober J, Tardini G, Wagner D and Team A U 2015 Plasma Physics and Controlled Fusion 57 ISSN 0741-3335;1361-6587

[10] Salewski M, Geiger B, Nielsen S K, Bindslev H, Garcia-Munoz M, Heidbrink W W, Korsholm S B, Leipold F, Madsen J, Meo F, Michelsen P K, Moseev D, Stejner M, Tardini G and Team A U 2013 Nuclear Fusion 53 ISSN 0029-5515 URL <Go to ISI>://WOS:000319421800019

[11] Jacobsen A S, Salewski M, Geiger B, Korsholm S B, Leipold F, Nielsen S K, Rasmussen J, Stejner M, Weiland M and Team A U 2016 Plasma Physics and Controlled Fusion 58 ISSN 0741-3335 URL <Go to ISI>://WOS: 000371818600002

[12] Rasmussen J, Nielsen S, Pedersen M, Galdon-Quiroga J, Garcia-Munoz M, Geiger B, Jacobsen A, Jaulmes F, Korsholm S, Lazanyi N, Leipold F, Ryter F, Salewski M, Schubert M, Stober $\mathrm{J}$ and Wagner D 2016 Nuclear Fusion 56112014 ISSN 0029-5515

[13] Stejner M, Nielsen S K, Bindslev H, Korsholm S B and Salewski M 2011 Plasma Physics and Controlled Fusion 53 ISSN 0741-3335

[14] Stejner M, Korsholm S B, Nielsen S K, Salewski M, Bindslev H, Leipold F, Michelsen P K, Meo F, Moseev D, Burger A, Kantor M and de Baar M 2012 The Review of scientific instruments 83 10E307 ISSN 1089-7623 URL http://link.aip.org/link/?RSINAK/83/10E307/1

[15] Stejner M, Nielsen S K, Jacobsen A S, Korsholm S B, Leipold F, McDermott R M, Michelsen P K, Rasmussen J, Salewski M, Schubert M, Stober J, Wagner D H and Team A U 2015 Plasma Physics and Controlled Fusion 57 ISSN 0741-3335;1361-6587

[16] Kubo S, Nishiura M, Tanaka K, Shimozuma T, Yoshimura Y, Igami H, Takahash H, Mutoh T, Tamura N, Tatematsu Y, Saito T, Notake T, Korsholm S B, Meo F, Nielsen S K, Salewski M and Stejner M 2010 The Review of scientific instruments 81 10D535 ISSN 1089-7623 URL http://link. aip.org.globalproxy.cvt.dk/link/?RSINAK/81/10D535/1

[17] Bin W, Bruschi A, D'Arcangelo O, Castaldo C, De Angeli M, Figini L, Galperti C, Garavaglia S, Granucci G, Grosso G, Korsholm S B, Lontano M, Mellera V, Minelli D, Moro A, Nardone A, Nielsen S K, Rasmussen J, Simonetto A, Stejner M and Tartari U 2015 Journal of Instrumentation 10 ISSN 1748-0221

[18] Salewski M, Nielsen S K, Bindslev H, Furtula V, Gorelenkov N N, Korsholm S B, Leipold F, Meo F, Michelsen P K, Moseev D and Stejner M 2011 Nuclear Fusion 51 ISSN 0029-5515

[19] Woskov P, Bindslev H, Leipold F, Meo F, Nielsen S K, Tsakadze E L, Korsholm S B, Scholten J, Tito C, Westerhof E, Oosterbeek J W, Leuterer F, Monaco F, Muenich M and Wagner D 2006 Review of Scientific Instruments 77 ISSN 0034-6748

[20] Wagner D, Grünwald G, Leuterer F, Manini A, Monaco F, Münich M, Schütz H, Stober J, Zohm H, Franke T, Thumm M, Gantenbein G, Heidinger R, Meier A, Kasparek W, Lechte C, Litvak A, Denisov G, Chirkov A, Tai E, Popov L, Nichiporenko V, Myasnikov V, Solyanova E, Malygin S, Meo F and Woskov P 2008 Nuclear Fusion 48054006 ISSN 0029-5515

[21] Furtula V, Salewski M, Leipold F, Michelsen P K, Korsholm S B, Meo F, Moseev D, Nielsen S K, Stejner M and Johansen T 2012 Review of Scientific Instruments 83 ISSN 0034-6748

[22] Stejner M, Nielsen S, Jacobsen A S, Korsholm S B, Leipold F, Meo F, Michelsen P K, Moseev 
D, Rasmussen J, Salewski M, Schubert M, Stober J, Wagner D H and Team A U 2014 Review of Scientific Instruments 85 ISSN 0034-6748;1089-7623

[23] Meo F, Stejner M, Salewski M, Bindslev H, Eich T, Furtula V, Korsholm S B, Leuterer F, Leipold F, Michelsen P K, Moseev D, Nielsen S K, Reiter B, Stober J, Wagner D and Woskov P 2010 Journal of Physics: Conference Series 227012010 ISSN 1742-6596 URL http://iopscience.iop.org.globalproxy.cvt.dk/1742-6596/227/1/012010

[24] Salewski M, Meo F, Stejner M, Asunta O, Bindslev H, Furtula V, Korsholm S, KurkiSuonio T, Leipold F, Leuterer F, Michelsen P, Moseev D, Nielsen S, Stober J, Tardini G, Wagner D and Woskov P 2010 Nuclear Fusion 50035012 ISSN 0029-5515 URL http://iopscience.iop.org.globalproxy.cvt.dk/0029-5515/50/3/035012

[25] Kjer Hansen S 2016 Parametric decay and anamosous scattering in asdex upgrade URL www. test.de

[26] Porkolab M 1978 Nuclear Fusion 18 367-413 ISSN 0029-5515 URL http://iopscience.iop.org.globalproxy.cvt.dk/0029-5515/18/3/008

[27] McDermott F S, Bekefi G, Hackett K E, Levine J S and Porkolab M 1982 Physics of Fluids 25 1488 ISSN 00319171 URL http://link.aip.org/link/?PFLDAS/25/1488/1

[28] Bowles K L 1958 Physical Review Letters 1(12) 454-455

[29] Salpeter E E 1960 Physical Review 1(5) 1528-1535

[30] Jassby D L, Cohn D R, Lax B and Halverso W 1974 Nuclear Fusion 14(5) 745-747 ISSN 0029-5515 URL ISI:A1974U705900018

[31] Behn R, Dicken D, Hackmann J, Salito S A, Siegrist M R, Krug P A, Kjelberg I, Duval B, Joye B and Pochelon A 1989 Physical Review Letters 62(24) 2833-2836

[32] Woskoboinikow P 1986 Review of Scientific Instruments 57 2113-2118

[33] Suvorov E V, Erckmann V, Holzhauer E, Kasparek W, Dryagin Y A, Filchenkov S E, Fraiman A A, Geist T, Kick M, Kukin L M, Kostrov A V, Lubyako L V, Shtanyuk A M, Skalyga N K and Smolyakova O B 1995 Plasma Physics and Controlled Fusion 37(11) 1207-1213

[34] Hoekzema J, Bindslev H, Egedal J, Fessey J, Gatcombe C, Hammond N, Hughes T, Machuzak J, JW O, Roberts P, Stevens A and Stott P 1997 Review of Scientific Instruments 68 275-280

[35] Stejner M, Nielsen S K, Korsholm S B, Salewski M, Bindslev H, Furtula V, Leipold F, Meo F, Michelsen P K, Moseev D, Buerger A, Kantor M and de Baar M 2010 Review of Scientific Instruments 81 ISSN 0034-6748

[36] Stejner M, Salewski M, Korsholm S B, Bindslev H, Delabie E, Leipold F, Meo F, Michelsen P K, Moseev D, Nielsen S K, Burger A, de Baar M and Team T 2013 Plasma Physics and Controlled Fusion 55 ISSN 0741-3335 URL <Go to ISI>://WOS:000322702700007

[37] Korsholm S B, Stejner M, Bindslev H, Furtula V, Leipold F, Meo F, Michelsen P K, Moseev D, Nielsen S K, Salewski M, de Baar M, Delabie E, Kantor M and Bürger A 2011 Physical Review Letters 106165004 ISSN 0031-9007 URL http://link.aps.org/doi/10.1103/PhysRevLett.106.165004

[38] Hutchinson D P, Vandersluis K L, Sheffield J and Sigmar D J 1985 Review of Scientific Instruments 56(5) 1075-1077 ISSN 0034-6748 URL ISI : A1985AJT6600120

[39] Machuzak J S, Woskov P P, Gilmore J, Bretz N L, Park H K, Aamodt R E, Cheung P Y, Russell D A and Bindslev H 1995 Review of Scientific Instruments 66(1) 484-486

[40] Bindslev H 1996 Journal of Atmospheric and Terrestrial Physics 58983

[41] Machuzak J, Woskov PP G J, Bretz N, Park H and Bindslev H 1997 Review of Scientific Instruments 68 458-461

[42] Bindslev H, Hoekzema J A, Egedal J, Fessey J A, Hughes T P and Machuzak J S 1999 Physical Review Letters 83(16) 3206-3209

[43] Nielsen S K, Bindslev H, Salewski M, Bürger A, Delabie E, Furtula V, Kantor M, Korsholm S B, Leipold F, Meo F, Michelsen P K, Moseev D, Oosterbeek J W, Stejner M, Westerhof E and Woskov P 2010 Plasma Physics and Controlled Fusion 52092001 ISSN 0741-3335 URL http://iopscience.iop.org.globalproxy.cvt.dk/0741-3335/52/9/092001

[44] Nielsen S, Salewski M, Bindslev H, Bürger A, Furtula V, Kantor M, Korsholm S, Koslowski H, Krämer-Flecken A, Leipold F, Meo F, Michelsen P, Moseev D, Oosterbeek J, Stejner M and Westerhof E 2011 Nuclear Fusion 51063014 ISSN 0029-5515 URL http://stacks.iop.org/0029-5515/51/i=6/a=063014

[45] Electron Cyclotron Resonance Heating on TEXTOR URL http://www. new.ans.org/pubs/journals/fst/a_692

[46] Jaulmes F, Geiger B, Odstril T, Weiland M, Salewski M, Jacobsen A, Rasmussen J, Pedersen M, Nielsen S and Westerhof E 2016 Nuclear Fusion 56 ISSN 0029-5515

[47] Shalashov A G, Suvorov E V, Lubyako L V, Maassberg H and Team t W A 2003 Plasma Physics and Controlled Fusion 45 395-412 ISSN 0741-3335 URL 
http://iopscience.iop.org.globalproxy.cvt.dk/0741-3335/45/4/306 